\title{
Mediações de leitura como estratégia para compreensão de textos por crianças de 6 anos em processo de alfabetização
}

\author{
Mediations of reading as a strategy for text comprehension by 6-year-old \\ children in the literacy process
}

\section{Las mediaciones lectoras como estrategia para la comprensión de textos en niños de 6 años en proceso de alfabetización}

Geisa Magela Veloso ${ }^{2}$

\begin{abstract}
Resumo: O artigo situa-se no contexto do letramento literário e tem por objetivo analisar as influências da leitura compartilhada de histórias para compreensão de textos por crianças de 6 anos, em processo de alfabetização. Com foco na literatura infantil procurou-se desenvolver condições para formar leitores fruidores da arte literária. Foi desenvolvida pesquisa-ação com realização de oficinas semanais de leitura compartilhada de textos literários, com crianças matriculadas no $1^{\circ}$ ano de escolaridade. Com o trabalho sistemático foram produzidas condições para a criança ouvir a leitura e compreender a linguagem escrita. Como resultados do estudo, constatou-se que as crianças puderam verbalizar sentimentos e percepções, antecipar sentidos, confirmar hipóteses, compreender, fazer inferências, desenvolver a sensibilidade e a criatividade, aguçar a curiosidade e a imaginação, ampliar conhecimentos, abrir-se para novos universos culturais e sociais.
\end{abstract}

Palavras-chave: Leitura de histórias. Alfabetização. Letramento literário. Compreensão de textos. Formação de leitores.

\begin{abstract}
This article is contextualized in literary literacy and aims to analyze the influences of shared storybook reading for reading comprehension by 6-year-old children in the literacy process. Focusing on children's literature we sought to develop conditions to form readers who enjoy literature. Action research was used with weekly shared reading workshops of literary texts, with children enrolled in the first year of school. With the systematic work, children were given conditions to listen to texts and understand written language. As a result of the study, we could notice that children could verbalize feelings and perceptions, anticipate senses, confirm hypotheses, understand, make inferences, develop sensitivity and creativity, sharpen curiosity and imagination, expand knowledge, open to new cultural and social universes.
\end{abstract}

Keywords: Reading stories. Literacy. Literary literacy. Understanding texts. Development of readers.

Resumen: El artículo se sitúa en el contexto del literal literario y tiene por objetivo analizar las influencias de la lectura compartida de historias para comprensión de textos por niños de 6 años, en proceso de alfabetización. Con foco en la literatura infantil se procuró desarrollar condiciones para formar lectores fruidores del arte literario. Se desarrolló investigación-acción con realización de talleres semanales de lectura compartida de textos literarios, con niños matriculados en el $1^{\circ}$ año de escolaridad. Con el trabajo sistemático se produjeron condiciones para que el niño oiga la lectura y comprenda el lenguaje escrito. Como resultados del estudio, se constató que los niños pudieron verbalizar sentimientos y percepciones, anticipar sentidos, confirmar hipótesis, comprender, hacer inferencias, desarrollar la sensibilidad y la creatividad, aguzar la curiosidad y la imaginación, ampliar conocimientos, abrirse a nuevos universos culturales y sociales.

Palabras clave: Lectura de historias. Alfabetización. Lector literario. Comprensión de textos. Formación de lectores.

\footnotetext{
${ }^{1}$ Submetido em: 02 maio 2019 - Aceito em: 28 jul. 2019 - Publicado em: 29 set. 2020

${ }^{2}$ Universidade Estadual de Montes Claros (UNIMONTES) - E-mail: velosogeisa@gmail.com
} 


\section{Introdução}

A pesquisa ${ }^{i}$ situa-se no campo de estudos sobre o letramento e tem a leitura compartilhada de literatura infantil como instrumento para o ensino-aprendizagem de habilidades letradas por crianças em processo de alfabetização. Consideramos com Soares (1998) a efetividade de se desenvolver práticas que visem alfabetizar letrando. Ou seja, ensinar a ler e escrever, ao mesmo tempo em que possibilita condições para as crianças desenvolverem as habilidades de uso social da leitura e escrita, delas fazendo uso em situações sociais.

Soares (1998) considera que a primeira condição para o letramento é que haja escolarização real e efetiva da população, que sejam criadas condições para que o sujeito alfabetizado tenha acesso aos materiais de leitura e escrita, posto que o letramento seja processo de inserção e participação na cultura escrita. Ainda, conforme Soares (1998, p. 39),

ter-se apropriado da escrita é diferente de ter aprendido a ler e escrever: aprender a ler e escrever significa adquirir uma tecnologia, a de codificar em língua escrita e de decodificar a língua; apropriar-se da escrita é tornar a escrita própria, ou seja, é assumi-la como sua propriedade.

Nesse contexto, o objetivo do artigo é analisar as influências da leitura compartilhada de histórias para a compreensão de textos por crianças de 6 anos, em processo de alfabetização. No desenvolvimento da pesquisa, as atividades realizadas visavam proporcionar às crianças a inserção no universo da literatura infantil e desenvolver a compreensão sobre os textos lidos; entendendo como Smith (2003), que a compreensão da leitura é a capacidade de responder questões específicas do texto, sendo capaz de interagir com o autor e sua obra. Isso significa dizer que, na realização das atividades, procuramos despertar nas crianças o desejo pela leitura, criar situações para compreensão do sistema de escrita e da linguagem, presente nos textos literários.

Com base em Solé (1998), consideramos a necessidade de ensinar estratégias de leitura - com intervenções antes, durante e depois de ler. Antes de ler, realizamos atividades para estabelecer previsões, elaboração de hipóteses e antecipações de sentido sobre os textos pela análise da superestrutura do livro, ilustrações, título, sublinhados, autoria -, que se constituíram como etapa importante no desenvolvimento da leitura. Em seguida, era realizada leitura em voz alta orientada pela estratégia de pausa protocolada, com suporte do projetor multimídia. Como procedimento didático foram realizadas atividades de análise do texto lido, confirmação de hipóteses e elaboração de novas previsões sobre o texto, apoiando as crianças em suas dificuldades. Após a leitura produzimos estratégias para sintetizar, resumir, responder perguntas, socializar sentidos acerca da história lida.

\section{Método}

O estudo organizou-se por uma abordagem qualitativa, orientada pela perspectiva metodológica da pesquisa-ação. Thiollent (1986) considera que a pesquisa-ação é uma 
modalidade que permite a organização de dados abrangentes, com possibilidade de experimentação da situação real. Por esta abordagem, o pesquisador intervém sobre a realidade estudada, com consciência do que pretende alterar e dos fenômenos e efeitos que pretende observar. Para o autor, "na pesquisa-ação os pesquisadores desempenham um papel ativo no equacionamento dos problemas encontrados, no acompanhamento e na avaliação das ações desencadeadas em função dos problemas" (THIOLLENT, 1986, p. 15).

Os sujeitos do estudo são crianças na faixa etária de 6 anos, matriculadas em duas turmas de $1^{\circ}$ ano de escolaridade, em uma escola pública localizada em bairro periférico da cidade de Montes Claros-MG. Como procedimentos metodológicos, realizamos entrevistas individuais, em dois momentos distintos - no início e no final do semestre letivo - visando diagnosticar as construções destes sujeitos, relacionadas ao nível conceitual de escrita, à presença de realismo nominal e habilidades de consciência fonológica, leitura e compreensão de textos. No entanto, nos limites deste artigo, discutiremos apenas as questões relativas ao processo de leitura e compreensão de textos.

No trabalho com as crianças, inicialmente, no mês de março de 2013, na primeira situação diagnóstica, solicitamos que fizessem a leitura do poema "O pardalzinho", de Manuel Bandeiraii . Caso a criança não soubesse ler convencionalmente, fazíamos exploração das imagens, procedíamos à leitura oral do poema e estabelecíamos uma conversa sobre o texto para identificação das habilidades de compreensão e inferência já desenvolvidas. Posteriormente, no mês de dezembro, reaplicamos a mesma situação diagnóstica, de forma a podermos estabelecer comparações acerca do desenvolvimento das crianças, sendo que, no decurso do ano letivo, realizamos rodas de leituras compartilhadas de histórias.

Essa opção metodológica - em que conhecer a realidade antecede o intervir sobre ela fundamentou-se em Bajard (2002). O autor afirma que, no processo de intervenção é necessário conhecer o meio onde pretende agir, posto que, sem esse conhecimento da realidade o pesquisador não obtém o engajamento dos atores no processo de formação. "Não seria legítimo começar o trabalho sem conhecer o terreno que se pretende modificar ou sem ter conquistado a confiança das pessoas com quem vai atuar" (BAJARD, 2002, p. 195).

No processo de imersão na escola procurou-se produzir a necessária relação de confiança entre pesquisadoras e sujeitos pesquisados, como também o distanciamento da realidade investigada para análise das ações e intervenções desenvolvidas. A opção, novamente, fundamentou-se em Bajard (2002), que aponta não haver contradição entre distanciamento e aproximação entre os sujeitos. Para o autor:

Uma das críticas feitas às pesquisas que pretendem modificar a realidade é considerar que haveria contradição entre uma postura de pesquisador que requer "distância" e o desejo de engajamento. No entanto, acreditar que a distância seria garantida pelo "desengajamento" é uma postura contestável (BAJARD, 2002, p. $193)$.

Portanto, por visar as aprendizagens dos alunos de seis anos, as mediações produzidas consideraram o estatuto social da infância e as produções culturais das crianças. Assim, como parte do processo de intervenção sobre a realidade, entre os meses de abril a novembro de 2013, foram desenvolvidas práticas semanais de leitura compartilhada de histórias e 
atividades para compreensão da escrita alfabética e apropriação de convenções do sistema de escrita, sempre às segundas-feiras, com duração aproximada de 90 minutos em cada turma, com presença e participação da professora regente da turma e duas graduandas em Pedagogia, bolsistas de iniciação científica. Nesse espaço-tempo eram lidos textos literários - contos de fadas, narrativas curtas, histórias compostas por imagens, lenga-lenga, poemas. As atividades se organizaram por metodologia de leitura que contemplou a antecipação de sentidos, a elaboração de hipóteses, a motivação e a definição de objetivos para ler, a exploração das ilustrações dos textos lidos - textos escaneados e projetados por equipamento multimídia -, a leitura mediada em voz alta, a socialização de sentidos e significados, como também atividades para alfabetização.

Nas atividades propostas, a voz de cada criança foi ouvida e sua ação considerada com seriedade, por se constituírem como aspectos indispensáveis de uma aprendizagem significativa e produtiva. Com Sarmento (2004) consideramos alguns pilares das culturas da infância. Nas rodas de leituras de histórias a interação entre as crianças, entre seus pares e os adultos se constituíram como eixo importante, o que permitiu a troca de experiências e ideias. Ao ler histórias para as crianças, a ludicidade foi considerada como dimensão central das culturas infantis, bem como a fantasia e a imaginação, que se constituem em uma especificidade dos mundos das crianças e se apresentaram como momentos em que experimentaram outras possibilidades de existência. Nessa discussão, Sarmento (2004) destaca a capacidade que crianças possuem em realizar uma transposição imaginária de objetos, pessoas ou situações.

Em todas as etapas da atividade com as crianças foi dada especial atenção aos valores, sentimentos, percepções, discursos, práticas e interesses, com o objetivo de compreender representações e respeitar o seu lugar e estatuto enquanto sujeitos sociais. Apesar de termos trabalhado com alfabetização e letramento, neste artigo colocamos foco no letramento literário, sendo que o texto se organiza por dois movimentos: na primeira seção apresentamos algumas bases teóricas que fundamentaram a investigação e, na segunda, discutimos dados produzidos junto às crianças.

\section{Base teórica para pesquisa e intervenções pedagógicas}

No processo de investigação e intervenção realizado com as crianças, orientamo-nos por conceitos produzidos no campo da alfabetização e do letramento. Entendemos com Soares (1998) que a alfabetização é um processo em que a criança desenvolve dois conjuntos de habilidades. De um lado, apropria-se do sistema de notação alfabética, o que inclui a capacidade de identificar letras e as distinguir dos números, compreender as idiossincráticas relações fonema-grafema, perceber o direcionamento da escrita, dentre outras capacidades. Por outro lado, a criança aprende sobre a língua que se usa para escrever, isto é, compreende a linguagem própria dos gêneros que circulam socialmente, percebe sua função social, entende que ler e escrever são práticas sociais e constituem-se como processo de interação e comunicação entre leitores e escritores. Em outras palavras, na acepção de Soares (1998), é necessário alfabetizar letrando. 
Para a autora, alfabetizar letrando significa ensinar a ler e escrever no contexto de práticas de leitura e escrita, de modo que o indivíduo alfabetizado seja capaz de fazer uso social das habilidades de ler e escrever. Também consideramos que alfabetizar e letrar são processos inseparáveis e complementares, em que nenhuma das ações antecede a outra. Assim, é necessário investimento para aprender a ler e escrever, mas também utilizar a leitura e a escrita, produzir significações, transitar pelo universo da cultura escrita, trabalhar com diferentes gêneros textuais. Também consideramos com Bortoni-Ricardo (2008, p. 83) que, em relação ao ensino da língua, "o desafio é saber desenvolver, com atividades pedagógicas e culturais, as redes neuronais do cérebro para que o aluno faça conexões para ler e escrever".

Com Ferreiro e Teberosky (1985), compreendemos que a alfabetização é uma aprendizagem de natureza conceitual, em que a criança constrói hipóteses e elabora conceituações, atribuindo significados aos textos e aos símbolos utilizados para escrever. Nesse processo de construção de conhecimento é importante a compreensão das relações entre fala e escrita, sendo que o ritmo de cada criança depende da sua imersão no mundo da escrita, da sua interação em práticas sociais em que se lê e se escreve. Por isso, é importante que o professor possa produzir situações didáticas estimulantes e significativas, em ambiente de alfabetização que permita a compreensão da linguagem escrita e a apropriação do sistema de representação alfabética pela criança.

Teberosky e Colomer (2003) afirmam que as crianças não aprendem por simples memorização, mas por elaboração de hipóteses, que são reconstruídas e se constituem como respostas aos verdadeiros problemas conceituais e não aos problemas infantis. E as hipóteses somente são elaboradas se a criança procurar entender esse objeto de conhecimento e tiver liberdade para produzir significados para os textos impressos, interagir com o material escrito, participar de práticas efetivas de leitura e escrita, interagir com textos e com leitores/escritores em diferentes formas e situações de uso do ler e do escrever.

Bajard (2002) lembra que a abordagem construtivista, que propõe o aprender fazendo, se constitui como postulado da Escola Nova e dos métodos ativos, no entanto, considera que não é tão simples colocar esta diretriz em prática.

A evidência da semelhança entre o alvo perseguido - o domínio da leitura - e a atividade realizada para adquiri-la é muitas vezes apenas superficial e não resiste a um exame aprofundado. É preciso conhecer a especificidade da atividade para poder adequar a aprendizagem visada à atividade proposta (BAJARD, 2002, p. 63).

Por isto, ao compreender o seu lugar e sua função, o professor prepara-se para o exercício de seu ofício em sala de aula. Para Bajard (2002), o professor tem um importante papel de mediador entre os textos e seus alunos, a ele cabe o lugar de orientador da escolha e da compreensão dos textos abordados na sua disciplina, assumindo a função de conduzir a aprendizagem da escrita por meio dos textos.

Estudos contemporâneos (MORAIS, 2006; FREITAS, 2004) indicam que as atividades alfabetizadoras, com efetividade para a apropriação do sistema de escrita, de um lado, permitem o desenvolvimento de habilidades metafonológicas das crianças, de forma que possam compreender as relações entre unidades gráficas e unidades sonoras. Por outro lado, o processo de alfabetizar letrando favorece a imersão da criança na cultura escrita, para 
compreender a linguagem, elaborar hipóteses sobre textos, reconstruir o sistema de representação alfabética. Assim, a utilização de elementos presentes no universo infantil, como textos literários, parlendas, trava-língua, trovas e outros textos que veiculem significações são essenciais, podem possibilitar o acesso ao mundo da cultura escrita, permitindo a exploração de elementos sonoros, como rimas, aliterações, sons iniciais e finais.

Ao discutir a inserção das crianças de seis anos no Ensino Fundamental, Frade (2007) afirma que o contato com a cultura escrita, desde a Educação Infantil, possibilita à criança construir um conjunto de representações mentais sobre escrita e leitura e o funcionamento da linguagem, essencial para sua alfabetização. A autora considera que não seja adequado excluir a interação oral ou as conversas compartilhadas em torno dos textos, posto que essas atividades permitem a compreensão do universo da linguagem, a ampliação do vocabulário, a fluência na leitura de textos. Para a autora, além de favorecer o processo de alfabetizar letrando, as histórias podem instigar reflexões sobre temas como solidariedade, injustiça social, autoritarismo entre outros, considerados como princípios basilares de convivência humana e, portanto, válidos para qualquer lugar, cultura e época.

Ao defender o acesso da criança ao universo da cultura escrita, Kramer (2010) afirma que a linguagem é central para o desenvolvimento humano, criando aprendizagem, construção e conhecimento, posto que se vincule à imaginação, ao diálogo, à expressão de saberes, afetos e valores. A autora lembra, ainda, que a linguagem constitui a consciência e organiza a conduta: nela e por meio dela são assimilados conceitos e preconceitos. Para garantir estas construções, Kramer (2010) considera fundamental assegurar o acesso das crianças e adultos às narrativas, músicas, desenhos, peças teatrais, dança e diversas formas de expressão literária: acalantos, trava-línguas, provérbios, fábulas, contos, mitos, lendas, romances. Nesse sentido, ao produzir o desejo de ler e escrever, as instituições responsáveis pela educação infantil desenvolvem a confiança da criança na sua capacidade de fazê-lo de forma saudável, prazerosa e competente.

Nessa direção, Machado (2007) considera que, para favorecer as aprendizagens significativas, as atividades de leitura são centrais na escola. Quando praticadas de forma não mecânica e instrumental, se constituem como um convite à leitura. Assim, no trabalho com as crianças, é importante dedicar tempo para as narrativas e para as rodas de leitura, que são condições para acesso aos livros. A autora lembra que ler, escrever e refletir sobre a vida humana, realizar leitura compartilhada do que se pensa, sente e vive é o que Walter Benjamin considera ser a leitura como experiência. Mais do que passatempo, trata-se de algo que ultrapassa o tempo de sua realização.

Neitzel (2007) considera que não é qualquer proposta de leitura que serve ao objetivo de ensinar a ler e aprender a gostar de ler. A experiência estética precisa estar fundada no equilíbrio entre a emoção e a cognição. Isso porque, conforme a autora, a literatura tem a possibilidade de promover não apenas a criatividade e a emoção, mas o pensamento lógico, a argumentação, capacidade de analisar, comparar, selecionar, julgar, planejar, organizar, experimentar, produzir, concluir etc. Citando pesquisas realizadas por diferentes autores, Neitzel (2007) afirma que o êxito dos projetos de leitura depende da concepção de literatura que norteia as ações e as metas propostas na escola. Para a autora, se quisermos despertar na 
criança o desejo de ler e escrever é necessário educá-la para a apreciação estética, levando-a a perceber o livro não apenas como instrumento de transmissão de conhecimentos, mas como instrumento lúdico e fruitivo. Nessa tarefa de formar leitores, Neitzel (2007) também considera necessário um acervo e uma abordagem que primem pela gratuidade de ler, desvencilhando o trabalho literário da pedagogia.

Enquanto autor de literatura infanto-juvenil, Albergaria (2000) também é favorável à leitura fruitiva e ao trabalho escolar que favoreça o despertar do desejo de ler em crianças e jovens; cabendo ao professor convidar o aluno à percepção da literariedade, das marcas que permitem perceber o jogo da ficção. Ao posicionar-se favoravelmente à leitura de literatura, o autor considera que o texto é uma necessidade do leitor; todos precisam de recolhimento, silêncio e momentos de solidão para exercer suas faculdades imaginativas e a literatura dá isto para o leitor. Ainda conforme o autor, a vantagem do texto literário é que contribui para formar o leitor mais hábil.

Por se constituir como atividade complexa e colocar desafios para o leitor, Solé (1998) discute estratégias necessárias ao ensino da leitura. Para a autora, a leitura é um processo mediante o qual o leitor empreende um movimento para compreender a linguagem escrita e produzir sentidos para os textos, sendo esta uma atividade que exige diferentes habilidades. A escola cumprirá a sua função mediadora ao atentar-se para a formação deste leitor "ativo", que realmente sabe ler e compreende a leitura, que maneja o texto com destreza, ultrapassa o nível da decodificação e aporta o texto com seus próprios objetivos, ideias e experiências prévias. Assim, a leitura propriamente dita é "aquela que realizam os leitores experientes e que nos motiva, é a leitura na qual nós mesmos mandamos: relendo, parando para saboreá-la ou para refletir sobre ela, pulando parágrafos... uma leitura íntima, e por isso, individual" (SOLÉ, 1998, p. 43).

Assim, é importante que, para as crianças, as primeiras experiências com texto se constituam como oportunidades de aprendizagem e não sejam marcadas pelo fracasso. Para Solé (1998), nos casos em que as práticas de leitura geram uma expectativa de fracasso, é muito difícil o leitor poder assumir o desafio que a leitura significa, sendo necessária uma intervenção que transforme as práticas em um sentido positivo para as crianças.

Focalizando a literatura infantil como possibilidade de formação dos leitores, em nossa investigação promovemos o acesso das crianças ao universo da literatura, espaço em que foi possível aguçar a curiosidade, fantasia, criatividade e imaginação, despertando o interesse para a leitura. Levando em consideração essas proposições teóricas foi organizado o processo de intervenção em sala de aula, visando desenvolver habilidades de letramento literário entre crianças de seis anos, em processo de alfabetização.

\section{Resultados do estudo}

Compreendemos que ao ouvir muitas histórias as crianças desenvolvem sua sensibilidade, imaginação, criatividade, fantasia, capacidade de leitura, dentre outras habilidades. Também constroem familiaridade com a linguagem escrita, ampliando 
conhecimentos, abrindo-se para novos universos culturais e sociais. Para Abramovich (1995, p. 16), “é importante para a formação de qualquer criança ouvir muitas, muitas histórias. Ouvir histórias é o início da aprendizagem para ser um leitor, e ser leitor é ter um caminho absolutamente infinito de descobertas e de compreensão do mundo". A autora afirma que os primeiros contatos com a literatura, normalmente, ocorrem com a audição de histórias, muitas vezes contadas pelos familiares e que despertam o interesse das crianças.

Por essa lógica, ao ler histórias na escola, o professor dá continuidade à processos e práticas já iniciados no ambiente familiar e social onde estão inseridas as crianças. Em muitos casos, a escola se constitui como espaço para as primeiras experiências com as histórias, sendo importante favorecer um contato prazeroso com a cultura escrita. As atividades de intervenção que realizamos junto às crianças se organizaram por essa lógica e foram iniciadas em abril de 2013, após o diagnóstico das habilidades, conhecimentos e dificuldades das crianças.

Semanalmente, foram realizadas atividades de leitura compartilhada de histórias. Considerando a metodologia adotada, inspirada em Solé (1988), em cada sessão de leitura, a primeira atividade sempre visava antecipar sentidos e ativar conhecimentos prévios das crianças, de forma a garantir condições para a compreensão da história e a construção de significações para o texto. Eram explorados elementos paratextuais - imagens e cores da capa, título da obra, autoria. A leitura era realizada oralmente, com suporte do projetor multimídia, que permitia às crianças visualizarem texto e imagens, ampliando possibilidade de compreensão do texto escrito, em que podiam confirmar ou descartar as hipóteses e elaborar novos sentidos para o texto. Após a leitura acontecia apreciação da história, sendo produzidas novas oportunidades para socialização de sentidos.

Para dar visibilidade para as construções das crianças, apresentamos alguns extratos de nosso diário de campo, breves relatos de atividades desenvolvidas na sala de aula, fragmentos de diálogos, que permitem compreender os pontos de vista das crianças. Como ponto de partida foi selecionado o livro "Uma historinha sem 1 sentido", de Ziraldo Alves Pinto (2002), visando despertar o gosto por ler, bem como sensibilizar as crianças para a leitura literária, discutir o valor atribuído ao saber ler e escrever, reconhecer as funções sociais da leitura no mundo contemporâneo. De forma leve e divertida, a obra narra aventuras de um herói que usa todos os sentidos para escapar das armadilhas de inimigos "transperigosos", mas morre "tost-queimado" em um incêndio, por não saber ler as instruções/advertências inscritas em uma placa.

As crianças gostaram da história, se envolveram com o personagem e sua luta heroica contra os inimigos, torceram e acreditaram na força do bem contra o mal. A cada página lida os alunos confirmaram hipóteses, antecipavam formas de ataque, pensaram estratégias de luta. Durante a leitura as crianças não perceberam a presença de palavras em inglês, inseridas na obra originalmente escrita em português - dark escuridão, rabit carro, open portas, danger fumacinha, the end fim. Na atividade de antecipação de sentido, as crianças não atentaram para a possibilidade de o livro abordar os sentidos humanos - paladar, tato, olfato, visão e audição -; tiveram dificuldades em perceber o diálogo intertextual com personagens das histórias em quadrinho - mulher coelho, Batman e Robin, presentes nas imagens da cozinha 
do herói e em expressões como bat-cozinha, cav-apartamento, infiel escudeiro. Mas, as crianças produziram múltiplas outras significações.

O desfecho da narrativa de Ziraldo surpreendeu a todos, ninguém antecipou a possibilidade de um herói analfabeto. E a sua morte provocou certa frustração. Na discussão que fizemos com as crianças foi construída a compreensão acerca da função social da leitura e das consequências trágicas da sua falta para o herói, mas não foi produzida uma discussão utilitária e moralizante da história, não foi proposta uma abordagem pedagógica de transposição da ficção para o real. As crianças compreenderam o drama do herói como fato ficcional, foram solidários, se identificaram, se sensibilizaram. E foram despertadas para o gosto pelas histórias, desejaram vivenciar outras conquistas, participar de outros dramas e lutas com novos e diferentes personagens.

No início do trabalho com as crianças, parte do grupo apresentou dificuldade em verbalizar, argumentar, produzir antecipações. $\mathrm{Na}$ audição das histórias e no compartilhamento de leituras subsequentes, as crianças revelaram outras dificuldades, mas, paulatinamente, foram se apropriando da linguagem escrita e produzindo processos mais elaborados de compreensão, interpretação e inferência sobre os textos lidos.

A leitura do livro "A bruxinha atrapalhada", de Eva Furnari (1982), nos permitiu observações importantes sobre as construções das crianças. O livro é organizado por uma série de pequenas histórias narradas apenas com a utilização de imagens, à semelhança dos HQs, sendo que os episódios se constituem por uma sucessão de cenas. Apesar de independentes, os episódios guardam elementos comuns entre si - a presença da bruxinha e do seu companheiro gato em uma cena inicial; a quebra da estabilidade cotidiana pelo aparecimento de algum elemento novo - passarinho, torneira, tartaruga etc -; o desejo da bruxinha em produzir alguma transformação; a trapalhada da personagem na execução do feitiço; a incorporação de características físicas do antigo objeto pelo novo objeto transformado pela bruxinha - o chapéu, originalmente passarinho, tem asas e voa; o banquinho, antes tartaruga, que caminha; o guarda-chuva, originado de uma torneira, que borrifa água.

Tais elementos narrativos geram uma estabilidade na estrutura das historietas de Furnari (1982), permitindo que as crianças elaborem hipóteses, imaginem, antecipem, produzam inferências e processos de compreensão.

No episódio de abertura do livro, denominado "O chapéu", o primeiro quadro mostra a bruxinha sentada em um banquinho de praça com sua varinha de condão. Próximo a ela está o gato e no alto da página está um passarinho. Em nosso trabalho, para organizar a leitura das cenas foram feitas algumas perguntas orientadoras, sendo que as respostas das crianças revelam a capacidade de articulação de informações para produzir e antecipar sentidos:

$\mathrm{P}$ - O que será que a bruxinha vai fazer com este passarinho?

C1 - Acho que vai transformar ele em chapéu.

$\mathrm{P}$ - Por que você acha que a bruxinha vai transformar o passarinho em um chapéu?

C1 - Ora, porque a história chama "o chapéu".

No final da história, quando o chapéu da bruxinha sai voando, as crianças novamente revelam a capacidade de articular as ideias para produzir inferências sobre o texto lido. 
P - Por que o chapéu da bruxinha voou?

C1 - Por que ele [chapéu] era um passarinho e ela [bruxinha] transformou ele [passarinho] num chapéu e ele [chapéu] voou porque ele era um passarinho.

No segundo episódio, denominado de "Oba! Olha lá!", o diálogo com as crianças é também bastante produtivo. As crianças produzem várias possibilidades de sentido para as imagens lidas. Na primeira cena está a bruxinha e o gato, que caminham em direção contrária a uma tartaruga que se encontra debaixo de uma árvore carregada de frutas:

$\mathrm{P}$ - O que será que a bruxinha vai fazer?

$\mathrm{C} 1$ - Ela vai comer a tartaruga.

C2 - Ela vai transformar a tartaruga em uma maçã.

C3 - Ela vai pegar uma vara e vai cutucar a maçã.

$\mathrm{C} 4$ - Eu acho que ela vai transformar a tartaruga em um serrote e vai serrar a árvore.

C4 - A bruxa tá precisando de uma vara para cutucar.

C5 - Ela vai subir no pé [de fruta].

C6 - Ela vai arranjar uma escada. É mais difícil na altura.

C7 - Ela [a bruxa] vai transformar ela [a árvore alta] em baixa.

Diante da constatação de que a bruxinha transformou a tartaruga em banquinho, foi questionado: será que a bruxinha vai conseguir pegar a maçã?

C1 - Vai.

C2 - Não, ela vai andar e por causa da mágica a bruxa vai cair.

C3 - Esses feitiços da bruxa não "dá" certo!

Diante da constatação de que o banquinho andou, foi questionado: por que será que o banco andou?

C1 - Porque a tartaruga tem perna. A bruxa não arrancou a perna dela.

Ao final do episódio uma criança produz uma síntese da história:

C4 - A bruxa e o gato "tava" andando. Aí ela viu uma maçã. Ela "tava" tentando pegar a maçã e não conseguiu. Ela viu a tartaruga e ficou olhando com a varinha na mão. Foi lá e olhou e fez o feitiço (Extrato do diário de campo, em outubro de 2013).

As respostas das crianças nos permitiram perceber as associações, as inferências, os processos de compreensão produzidos. As respostas revelam que as crianças estavam atentas aos muitos elementos que constroem as narrativas, percebendo que os sentidos não são desarticulados dos textos e das intenções do autor. E nesse processo construtivo, no mês de novembro, o trabalho com "A Máquina Maluca", livro de Ruth Rocha (2010), ilustrado por Mariana Massarani, permitiu uma atividade rica e intensa, de produção de significados e inferências, de diálogo e interação das crianças com a obra e seus autores.

Ao serem instigadas a analisar a capa do livro, as crianças se manifestaram:

C1 - Será por que ela [a máquina] está brilhando?

C2 - Eu acho que já sei. É porque o homem criou o robô e ele tá brilhando.

C3 - Deve ser que tem um problema na máquina.

C4 - Eu acho que a máquina tá cantando, porque tem essas coisas aí [notas musicais na capa do livro].

C5 - Ela tá balançando.

$\mathrm{P}$ - O que será que vai acontecer de maluco com a máquina?

C6 - A máquina vai pegar fogo.

C7 - Ela fica maluca e todo mundo fica correndo.

P - Quem será que inventou essa máquina?

C8 - Ruth Rocha.

C9 - Não foi Ruth Rocha, ela é autora. Foi o cientista maluco.

C10 - Eu acho que foi o cientista.

$\mathrm{P}$ - Para que serve a máquina?

C11 - Para derrotar o mundo. 
C12 - Para fazer o poder da morte.

C13 - Ela vai fazer um "tantão" de coisa para ajudar eles.

C14 - Ela tá fazendo é assustar as pessoas.

As crianças também faziam perguntas sobre o que viam nas ilustrações, visando compreender o texto.

C1 - Por que será que o bebê está chorando?

$\mathrm{P}$ - O que você acha?

C1 - Eu acho que tem duas opções: a máquina tá querendo o leite dele; ele tá com medo da máquina.

P - Então, vamos ler o texto para descobrir por que o bebê está chorando?

Diante da indagação acerca dos pedidos inusitados da máquina, as crianças produziam diferentes respostas.

P - Para que a máquina quer óleo de bronzear?

C3 - Para passar nela.

C5 - Para usar de combustível.

C1 - Para ela usar na Bahia. Não é lá que tem aquele rio para nadar?

Nessa construção, a criança revela que compreendera o texto e também elaborava inferências. A partir das informações da história, ela conclui que a máquina queria óleo de bronzear para ir para a Bahia, tomar banho de mar e se bronzear na praia.

No decorrer da história, quando a máquina passou a fazer exigências (óleo de bronzear, perucas com mechas louras, perfume francês, fantasia de carnaval), uma criança elabora questionamentos bastante sensatos, apesar de revelarem um certo rompimento com o pacto ficcional.

C1 - Eu não estou entendendo essa máquina! Se ela sabe fazer tudo, por que ela pede as coisas para as pessoas? Ela pode fazer todas essas coisas (Extrato do diário de campo, em 18 de novembro de 2013).

As respostas das crianças mostram que não apenas compreendiam as ideias narradas nas páginas do livro, mas também estabeleciam relações entre elas, questionavam, duvidavam, conectavam o texto com seus conhecimentos prévios e produziam inferências.

Em nosso processo de pesquisa e de atividades com as crianças foi realizada entrevista para diagnóstico final, em dezembro de 2013. A atividade se constituiu da leitura autônoma do poema "O pardalzinho", de Manuel Bandeira, que havia sido proposto no diagnóstico inicial, sendo que após ler, as crianças foram solicitadas a falar sobre o que compreenderam do texto. Foram muitas as respostas e posicionamentos, que revelam variados processos construtivos, distintos ritmos de aprendizagem. Para exemplificar, citamos um único extrato de entrevista, representativo desta diversidade de aprendizagens.

$\mathrm{P}$ - O que você entendeu deste poema lido?

C - Era uma vez um passarinho muito livre. Ele adorava ser livre. Um dia ele quebrou sua asa. Ele encontrou uma menina para cuidar dele, mas ela cuidava mal. Ela não dava muita comida. Aí, ele morreu e foi pro céu dos passarinhos.

A criança utilizou a estratégia de narrar para falar sobre o que entendeu com sua leitura, transformando o poema em texto narrativo - provavelmente por se apoiar nas experiências de contação de histórias vivenciadas no decurso do ano letivo.

Ao terminar o reconto, a criança se posiciona sobre o poema e nos dirige uma indagação:

C - Não tem um texto mais feliz, não? Este é muito triste!

$\mathrm{P}$ - Você não gostou deste texto?

C - Não, porque o passarinho morreu.

$\mathrm{P}$ - Antes de morrer o passarinho ganhou uma casa. Como será a casa que Sacha deu para o passarinho? 
C - Ela deu a casa dela pra ele morar lá. Ah, não, não é isso! É uma jaula. Não, não é jaula, não. Como é o nome daquele negócio que eles vendem para colocar o passarinho?

P - Gaiola.

C - É isso, ele não gostou da gaiola, porque ele adorava ser livre.

Não satisfeita com suas próprias respostas, a menina leu de novo um trecho do poema e disse:

C - Agora eu entendi. Ele morreu por causa que não gostava de ser preso. Ele nasceu para ficar livre. Por que inventaram gaiola? (Extrato de caderno de campo, entrevista realizada em 02 de dezembro de 2013).

Neste extrato é possível perceber que a criança não apenas compreendeu as principais ideias do poema, mas também fez inferências e se posicionou. Em alguns momentos, ao falar sobre o texto, a menina percebe o equívoco da sua interpretação, retoma o texto, relê alguns trechos e se corrige. Para Solé (1998), as lacunas (a sensação de não estar compreendendo o texto) e os erros de compreensão (falsas interpretações) podem ocorrer durante a atividade de leitura. No entanto, um obstáculo de leitura (não compreender algo) nem sempre é preocupante. Podemos não compreender um parágrafo, mas captarmos o sentido global do texto sem problema. Mas, o ato de ler as cláusulas de um contrato, por exemplo, e não compreendermos bem, pode gerar uma necessidade de retomada do texto para garantir a compreensão.

Em nosso estudo, as dificuldades das crianças sinalizam os investimentos pedagógicos e as intervenções pedagógicas que se fazem necessárias, de forma a apoiar as aprendizagens. Em nossas interlocuções com as crianças, muitas foram as construções - construções que não se circunscrevem nos extratos aqui apresentados, que não cabem nos limites de um artigo científico, pois se constituem nos e pelos processos cognitivos, pela inventividade e inteligência das crianças participantes do estudo.

\section{Conclusão}

A pesquisa nos permitiu perceber que a leitura compartilhada de histórias pode se constituir como importante estratégia de ensino para as crianças em processo de alfabetização, mas que ainda não sabem ler de forma autônoma. As atividades realizadas mostraram que as crianças produziram muitas aprendizagens, que não se processariam sem esta ferramenta. As crianças desenvolveram habilidades diversas, relacionadas à oralidade, à compreensão da linguagem escrita, ao gosto por livros de histórias, ao desejo por aprender a ler.

As crianças aprenderam que as histórias podem ser identificadas por seu título e que estas têm um autor e um ilustrador; aprenderam a ler as ilustrações e se apoiar em índices textuais verbais e não verbais para compreender e inferir. No contraponto da fala, aprenderam a ouvir e respeitar posicionamentos, a argumentar e negociar pontos de vista.

Para recontar a história ouvida, as crianças também fizeram construções importantes: lembrar o enredo, organizar as ideias, fatos e ocorrências principais na sequência em que 
ocorreram e foram narrados no livro, estruturar as frases para poder dizer aos colegas, dentre outras habilidades.

O compartilhamento de histórias favoreceu o desenvolvimento da iniciativa e da argumentação. A atividade também possibilitou a participação nos debates e nas conversas ocorridas na sala de aula, favoreceu a desinibição e ampliação da capacidade expressiva das crianças, para poderem se manifestar publicamente, se posicionar frente aos colegas, apresentar seus pontos de vista.

\section{Referências}

ABRAMOVICH, Fanny. Literatura infantil: gostosuras e bobices. São Paulo: Scipione, 1995.

ALBERGARIA, Lino de. Literatura e escola. Revista Presença Pedagógica, Belo

Horizonte, v. 6, n. 36, p. 40-47, nov./dez. 2000.

BAJARD, Élie. Caminhos da escrita: espaços de aprendizagem. 2. ed. São Paulo: Cortez Editora, 2002.

BANDEIRA, Manuel. O pardalzinho. In: BANDEIRA, Manuel (org.). Lira dos cinquent'anos. 1. ed. digital. São Paulo: Global Editora, 2014. p. 51.

BORTONI-RICARDO, Stella Maris. O professor pesquisador: introdução à pesquisa qualitativa. São Paulo: Parábola Editorial, 2008.

FERREIRO, Emilia; TEBEROSKY, Ana. A psicogênese da Língua Escrita. Porto Alegre: Artes Médicas, 1985.

FRADE, Isabel Cristina Alves da Silva. Alfabetização na escola de nove anos: desafios e rumos. In: SILVA, Ezequiel Theodoro (org.). Alfabetização no Brasil: questões e provocações da atualidade. Campinas: Autores Associados, 2007. p. 73-112.

FREITAS, Gabriela Castro Menezes de. Sobre a consciência fonológica. In: LAMPRECHT, Regina Ritter et al. (org.). Aquisição fonológica do português: perfil de desenvolvimento e subsídios para a terapia. Porto alegre: Artmed, 2004. p. 177-192.

FURNARI, Eva. A bruxinha atrapalhada. São Paulo: Editora Global, 1982.

KRAMER, Sonia. O papel da educação infantil na formação do leitor: descompassos entre as políticas, as práticas e a produção acadêmica. In: DALBEN, Ângela et al. (org.).

Convergências e tensões no campo da formação e do trabalho docente: alfabetização e letramento [...]. Belo Horizonte: Autêntica, 2010. p. 111-133.

MACHADO, Cila Alves dos Santos. Estratégias pedagógicas de linguagem escrita na educação infantil: intencionalidade e foco. In: FERREIRA, Valéria Silva (org.). Infância e linguagem escrita: práticas docentes. Itajaí: UNIVALI, 2007. p. 201-217. 
MORAIS, Artur Gomes de. Consciência fonológica e metodologias de alfabetização. Revista Presença Pedagógica, Belo Horizonte, v. 12, n. 70, p. 58-67, jul./ago. 2006.

NEITZEL, Adair de Aguiar. Prosa \& poesia na literatura infantil: a literatura pede passagem. In: FERREIRA, Valéria Silva (org.). Infância e linguagem escrita: práticas docentes. Itajaí: UNIVALI, 2007. p. 25-44.

PINTO, Ziraldo Alves. Uma historinha sem 1 sentido. São Paulo: Melhoramentos, 2002.

ROCHA, Ruth. A máquina maluca. Ilustração de Mariana Massarani. São Paulo: Editora Salamandra, 2010.

SARMENTO, Manuel Jacinto. As culturas da infância nas encruzilhadas da $2^{\mathrm{a}}$ modernidade. In: SARMENTO, Manuel Jacinto; CERISARA, Ana Beatriz (org.). Crianças e Miúdos: perspectivas sociopedagógicas da infância e educação. Porto: Asa, 2004. p. 9-34.

SMITH, Frank. Compreendendo a leitura: uma análise psicolinguística da leitura e do aprender a ler. Tradução de Daise Batista. Porto Alegre: Artmed, 2003.

SOARES, Magda. Letramento: um tema em três gêneros. 1. ed. Belo Horizonte: Autêntica, 1998.

SOLÉ, Isabel. Estratégias de leitura. Porto Alegre: Artmed, 1998.

TEBEROSKY, Ana; COLOMER, Tereza. Aprender a ler e escrever: uma proposta construtivista. Porto Alegre: Artmed, 2003.

THIOLLENT, Michel. Metodologia da pesquisa-ação. 2. ed. São Paulo: Cortez: Autores Associados, 1986.

\section{Notas}

${ }^{i}$ O projeto de pesquisa foi aprovado pelo Comitê de Ética da Unimontes, sob parecer $n^{\circ}$ 2731/11, em conformidade com a Resolução 196/96, do Conselho Nacional de Saúde. Na realização de atividades de pesquisa participaram as graduandas: Delma Pereira dos Santos, Gisele Cunha Oliveira, Rozeli dos Santos Andrade.

ii "O Pardalzinho" - Manuel Bandeira (2014). "O pardalzinho nasceu livre / Quebraram-lhe a asa / Sacha lhe deu uma casa / Água, comida e carinhos / Foram cuidados em vão / A casa era uma prisão / O pardalzinho morreu / O corpo Sacha enterrou no jardim / A alma, essa voou / Para o céu dos passarinhos!"

\section{Agradecimentos}

A pesquisa contou com apoio da Fundação de Amparo à Pesquisa do Estado de Minas Gerais - FAPEMIG.

Checagem Antiplágio

Crossref

Similarity Check
Distribuído sobre

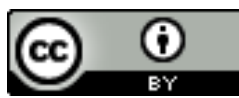

